\title{
Seismic Assessment of Cold-Formed Steel Stud Bracing Wall Panels Using Direct Displacement Based Design Approach
}

\author{
Rojit Shahi ${ }^{1,},+$, Nelson Lam ${ }^{1}$, Emad Gad $^{2}$, John Wilson ${ }^{3}$ and Ken Watson ${ }^{4}$ \\ ${ }^{1}$ Department of Infrastructure Engineering, The University of Melbourne, Parkville, Victoria \\ 3010, Australia \\ ${ }^{2}$ Department of Civil and Construction Engineering, Swinburne University of Technology, \\ Hawthorn, Victoria 3122, Australia \\ ${ }^{3}$ Faculty of Science Engineering and Technology, Swinburne University of Technology, \\ Hawthorn, Victoria 3122, Australia \\ ${ }^{4}$ National Association of Steel-Framed Housing Inc (NASH), Hartwell, Victoria, 3124, \\ Australia
}

\begin{abstract}
An important advancement in structural engineering in recent years has been the development of performance-based design (PBD). However, its application to cold-formed steel framed buildings remains largely unexplored. This paper presents the assessment of the bracing capacity of cold-formed steel stud bracing wall panels using a direct-displacement based design (DDBD) approach. The fundamentals of DDBD using equivalent damping, and inelastic displacement response spectra approaches are presented. These wall parameters needed for each approach are evaluated from experimental load-deflection response behaviour under quasi-static cyclic loading. Results obtained from the DDBD approach are compared with results from conventional non-linear time history analyses (NLTHA) to confirm the validity of the adopted approach. It is found that results estimated from DDBD method using inelastic displacement response spectra approach correlated much better with NLTHA results than the equivalent damping method.
\end{abstract}

Keywords Bracing capacity; cold-formed steel stud bracing wall panels; direct-displacement based design; equivalent damping; inelastic displacement response spectra; non-linear time history analyses

\section{Introduction}

Current seismic design methods in Australia and many other parts of the world are based on the conventional force-based (FB) design procedure, which is mainly concerned with the adequacy of lateral strength of the structure to withstand the projected seismic actions. Considering strength requirements of the structure alone would not ensure optimal design given that damage to structural, and non-structural, components is well correlated with lateral displacement demand that are resulted from earthquake ground shaking. One of the major advances in seismic design over the past two decades is performance-based design (PBD) which enables practitioners to design structures that have predictable performance against

Correspondence to: Rojit Shahi, Department of Infrastructure Engineering, The University of Melbourne,

Parkville, Victoria 3010, Australia.

+Email: rojit.shahi@unimelb.edu.au 
earthquake ground shaking. Given that most types of damage to the structure is associated with displacement demand, new methodologies which are based on the considerations of displacements as the main factor for design have been developed and are known as the displacement-based design (DBD) method. Analyses based on the use of the direct displacement-based design (DDBD) approach have been implemented on several structural systems such as reinforced concrete buildings and bridges (Priestley 1993, 1998, 2000). However, the methodology has never been adapted for the design of cold-formed steelframed buildings. Resistance against lateral loadings such as earthquake in the cold-formed steel-framed buildings are mainly provided by ceiling diaphragm (horizontal element) and bracing wall panels (vertical element). Behaviour of these elements against seismic loading can be highly nonlinear and subject to significant strength degradation following several cycles of load reversals (Landolfo et al. 2006, Nithyadharan \& Kalyanaraman 2012, Shahi et al. 2016). This paper presents the fundamentals of the DDBD approach and its application for assessing the bracing capacity of cold-formed steel stud bracing wall panels. Different versions of the design approach are evaluated herein for comparison with results from NLTHA.

\section{Fundamentals of Direct displacement-based design (DDBD) Approach}

Seismic design of a structure employing DDBD is based on a certain pre-defined target displacement value for a given level of seismic hazard. The structure is modelled as a singledegree-of-freedom (SDOF) system possessing effective stiffness $\left(\mathrm{K}_{\mathrm{eff}}\right)$ and equivalent viscous damping $\left(\xi_{\mathrm{eq}}\right)$ properties that are considered to be representative of the global behaviour of the structure at a targeted level of displacement $\left(\Delta_{t}\right)$. Alternatively, an inelastic displacement response spectrum can be used for determining the displacement demand value which is dependent on the value of the displacement ductility demand (Priestley et al. 2007). This study considers both the equivalent viscous damping approach and the inelastic response spectrum approach forming part of the DDBD methodology for assessing the bracing capacity of cold-formed steel stud bracing wall panels. Central to the modelling methods is the development of a DDBD curve, or mass restrained vs displacement curve for assessing the seismic performance of a wall panel built of cold-formed steel (refer also numerical example in Section 3). The term "mass restrained" which is to be used in the rest of the paper refers to the amount of tributary mass that is restrained by the wall panel for a given displacement demand value. The bracing capacity of the wall panel is expressed in terms of its strength demand requirement with the force-based method of design. In contrast, the bracing capacity of the wall panel is expressed in terms of the amount of mass restrained at a given level of target displacement with the DDBD method of design. Designers/practitioners can simply make use of these curves for estimating the bracing capacity of the wall panel in terms of the amount of mass that can be restrained by the wall panel at a predetermined design displacement demand at the ultimate limit state (ULS) or, at $1.5 \%$ inter-storey drift limit (AS1170.4 2007) whichever is the less. Designers can also make use of these curves for estimating the allowable value of displacement demand that an existing wall panel of a given seismic weight can sustain. However, this study has not considered interactions between bracing wall panels that may have an influence on their collective performance behaviour. The effects of such interactions are difficult to generalise as they could be dependent on the ductility of the wall panels, displacement compatibility, and also contributions from the return/intersecting walls. 


\subsection{Procedure for deriving DDBD curves based on the equivalent damping approach}

Figure 1 presents a flow chart of the procedure for generation of the DDBD curve of a wall panel. An equivalent viscous damping value has been incorporated in the assessment in order to capture the energy dissipation characteristics of the structure at a pre-defined target displacement limit. Bracing capacity of the wall panel is expressed in terms of the amount of mass that can be restrained at various levels of racking displacement. A step-by-step procedure for generating a DDBD curve is briefly described as follows:

Step 1. Derive the Equivalent Energy Elastic-Plastic (EEEP) curve from an experimental load-deflection (backbone) curve for the wall panel. Refer (Shahi et al. 2016) for details on how the EEEP curve can be derived from an experimental loaddeflection backbone curve.

Step 2. Select the target displacement demand $\left(\Delta_{t}\right)$, which can be any value between the yield displacement $\left(\Delta_{\mathrm{Y}}\right)$ and the ultimate limit state displacement $\left(\Delta_{\mathrm{U}}\right)$.

Step 3. Find value of effective stiffness $K_{\text {eff }}=R_{U} / \Delta_{t}$ from the EEEP curve at $\Delta_{t}$ where $R_{U}$ is the yield, or ultimate, strength. Then, calculate the equivalent viscous damping value by using Eq. (1).

$\xi_{\mathrm{eq}}=\frac{\mathrm{E}_{\mathrm{D} \Delta_{\mathrm{t}}}}{2 \pi \mathrm{K}_{\mathrm{eff}} \Delta_{\mathrm{t}}^{2}}$

where,

$\mathrm{E}_{\mathrm{D} \Delta_{\mathrm{t}}}=$ Energy dissipated per cycle at the target displacement demand $\left(\Delta_{\mathrm{t}}\right)$ obtained from the relevant hysteretic model

Step 4. Quantify the seismic hazard. Domestic structures in Australia are designed for a return period of 500 years at ultimate limit state. The seismic hazard of a given seismic zone can be expressed in the form of an elastic displacement response spectrum. Refer Eq. (2) for the relationship between response spectral acceleration and displacement. Code spectral values are typically specified for an equivalent viscous damping value of $5 \%$. The spectral displacement values corresponding to the actual equivalent viscous damping level of the structure at target displacement can be obtained through empirical modification factor $\left(\mathrm{R}_{\xi \mathrm{eq}}\right)$ (Lam et al. 2001) for conditions of single resonance (i.e. without soil-rock resonance). It is noted that the value of the modification factor obtained by the use of Eq. (4) is closer to that recommended by Eurocode 8 (EN 1998-1 2004).

$\mathrm{S}_{\mathrm{D} \text { Code }}=\frac{\mathrm{T}_{1}^{2}}{4 \pi^{2}} \times \mathrm{S}_{\mathrm{A} \text { Code }}$ 


$$
\begin{aligned}
& \left(\mathrm{S}_{\mathrm{D} \text { Code }}\right)_{\xi \mathrm{eq}}=\mathrm{S}_{\mathrm{D} \text { Code }} \times \mathrm{R}_{\xi \mathrm{eq}} \\
& \mathrm{R}_{\xi \mathrm{eq}}=\left(\frac{0.05}{\xi_{\mathrm{eq}}}\right)^{3}
\end{aligned}
$$

where,

$\mathrm{S}_{\mathrm{D} \text { Code }}=$ Code design elastic response spectral displacement

$\mathrm{S}_{\mathrm{A} \text { Code }}=$ Code design elastic response spectral acceleration

$\mathrm{T}_{1}=$ Elastic natural period of vibration of the building

$\left(\mathrm{S}_{\mathrm{D} \text { Code }}\right)_{\xi \mathrm{eq}}=$ Spectral displacement to the equivalent viscous damping $\left(\xi_{\mathrm{eq}}\right)$ of the structure at target displacement demand $\left(\Delta_{t}\right)$

$\mathrm{R}_{\xi \mathrm{eq}}=$ Modification factor corresponding to the equivalent viscous damping value of $\xi_{\mathrm{eq}}$

Step 5. Determine the value of the effective period ( $\left.\mathrm{T}_{\text {eff }}\right)$ from the displacement response spectra corresponding to an equivalent viscous damping value $\left(\xi_{\mathrm{eq}}\right)$ and the target displacement value $\left(\Delta_{\mathrm{t}}\right)$.

Step 6. Calculate the amount of mass that can be restrained $\left(\mathrm{M}_{\mathrm{R}}\right)$ by the wall panel at the selected target displacement $\left(\Delta_{\mathrm{t}}\right)$ using Eq. (5).

$\mathrm{M}_{\mathrm{R}}=\frac{\mathrm{K}_{\mathrm{eff}} \mathrm{T}_{\mathrm{eff}}^{2}}{4 \pi^{2}}$

Step 7. Select other values of target displacement demand, and for each values of the targeted demand, repeat steps 1 to 6 for calculation of the amount of mass that can be restrained.

Step 8. Plot the amount of mass that can be restrained and the corresponding target displacement value for generation of the DDBD curve. 


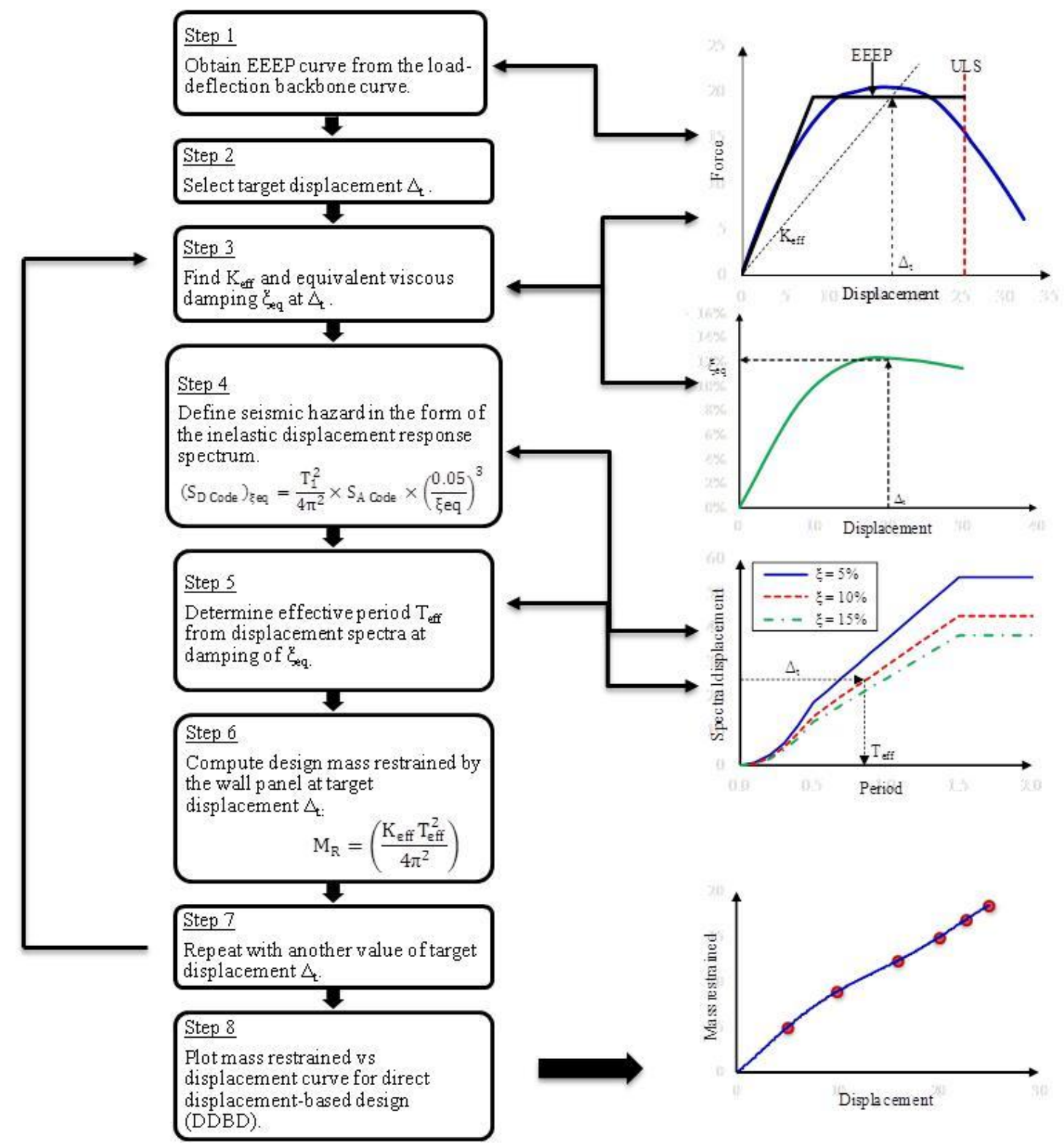

Fig. 1 Generation of DDBD curve based on equivalent damping approach

\subsection{Procedure for deriving DDBD curves based on inelastic displacement response spectrum approach}

Figure 2 presents a flow chart illustrating the steps for the generation of the DDBD curve of a wall panel. Inelastic displacement response spectra have been incorporated into the assessment method in order to capture the ductility demand behaviour of the structure at a pre-defined target displacement value. The bracing capacity of the wall panel is expressed in terms of the amount of mass that can be restrained at various levels of racking displacement. A step-by-step procedure for the generation of the DDBD curve is briefly described as follows:

Step 1. Derive the Equivalent Energy Elastic-Plastic (EEEP) curve from an experimental load-deflection (backbone) curve of the wall panel. Refer (Shahi et al. 2016) for 
details on how the EEEP curve can be derived from an experimental loaddeflection backbone curve.

Step 2. Select the target displacement demand $\left(\Delta_{t}\right)$, which can be any value between the yield displacement $\left(\Delta_{\mathrm{Y}}\right)$ and the ultimate limit state displacement $\left(\Delta_{\mathrm{U}}\right)$.

Step 3. Calculate structural ductility factor $\mu=\Delta_{\mathrm{t}} / \Delta_{\mathrm{Y}}$ and effective stiffness $\mathrm{K}_{\mathrm{eff}}=\mathrm{R}_{\mathrm{U}} / \Delta_{\mathrm{t}}$ from the EEEP curve at $\Delta_{\mathrm{t}}$ where $\mathrm{R}_{\mathrm{U}}$ is the yield, or ultimate, strength.

Step 4. Define the seismic hazard which can be represented in the form of the elastic displacement response spectrum shown in Eq. (6). The inelastic displacement response spectrum is then obtained by multiplying the corresponding elastic response spectral displacement values by the modification factor $\mathrm{R}_{\mu}$ as defined by Eq. (8) which is function of structural ductility factor $(\mu)$. The value of $\mu$ is in turn dependent on the value of $\Delta_{t}$.

$$
\begin{aligned}
& \mathrm{S}_{\mathrm{D} \text { Code }}=\frac{\mathrm{T}_{1}^{2}}{4 \pi^{2}} \times \mathrm{S}_{\text {A Code }} \\
& \left(\mathrm{S}_{\mathrm{D} \text { Code }}\right)_{\mu}=\mathrm{S}_{\mathrm{D} \text { Code }} \times \mathrm{R}_{\mu} \\
& \mathrm{R}_{\mu}=\left(\frac{1}{\mu}\right)^{0.5}
\end{aligned}
$$

where,

$\mathrm{S}_{\mathrm{D} \text { Code }}=$ Code design elastic response spectral displacement

$\mathrm{S}_{\mathrm{A} \text { Code }}=$ Code design elastic response spectral acceleration

$\mathrm{T}_{1}=$ Elastic natural period of vibration of the building

$\left(\mathrm{S}_{\mathrm{D} \text { Code }}\right)_{\mu}=$ Inelastic response spectral displacement which is dependent on structural ductility factor $(\mu)$

$\mathrm{R}_{\mu}=$ Modification factor corresponding to the structural ductility factor $(\mu)$

Step 5. Determine the value of the effective period ( $\left.\mathrm{T}_{\text {eff }}\right)$ from the inelastic displacement response spectra corresponding to the value of $\Delta_{t}$.

Step 6. Calculate the amount of mass that can be restrained $\left(\mathrm{M}_{\mathrm{R}}\right)$ by the wall panel at the selected target displacement $\left(\Delta_{\mathrm{t}}\right)$ using Eq. (9).

$\mathrm{M}_{\mathrm{R}}=\frac{\mathrm{K}_{\mathrm{eff}} \mathrm{T}_{\mathrm{eff}}^{2}}{4 \pi^{2}}$

Step 7. Select other values of target displacement demand, and for each values of the targeted demand, repeat steps 1 to 6 for calculating the amount of mass that can be restrained. 
Step 8. Plot the amount of mass restrained and the corresponding target displacement for generation of the DDBD curve.

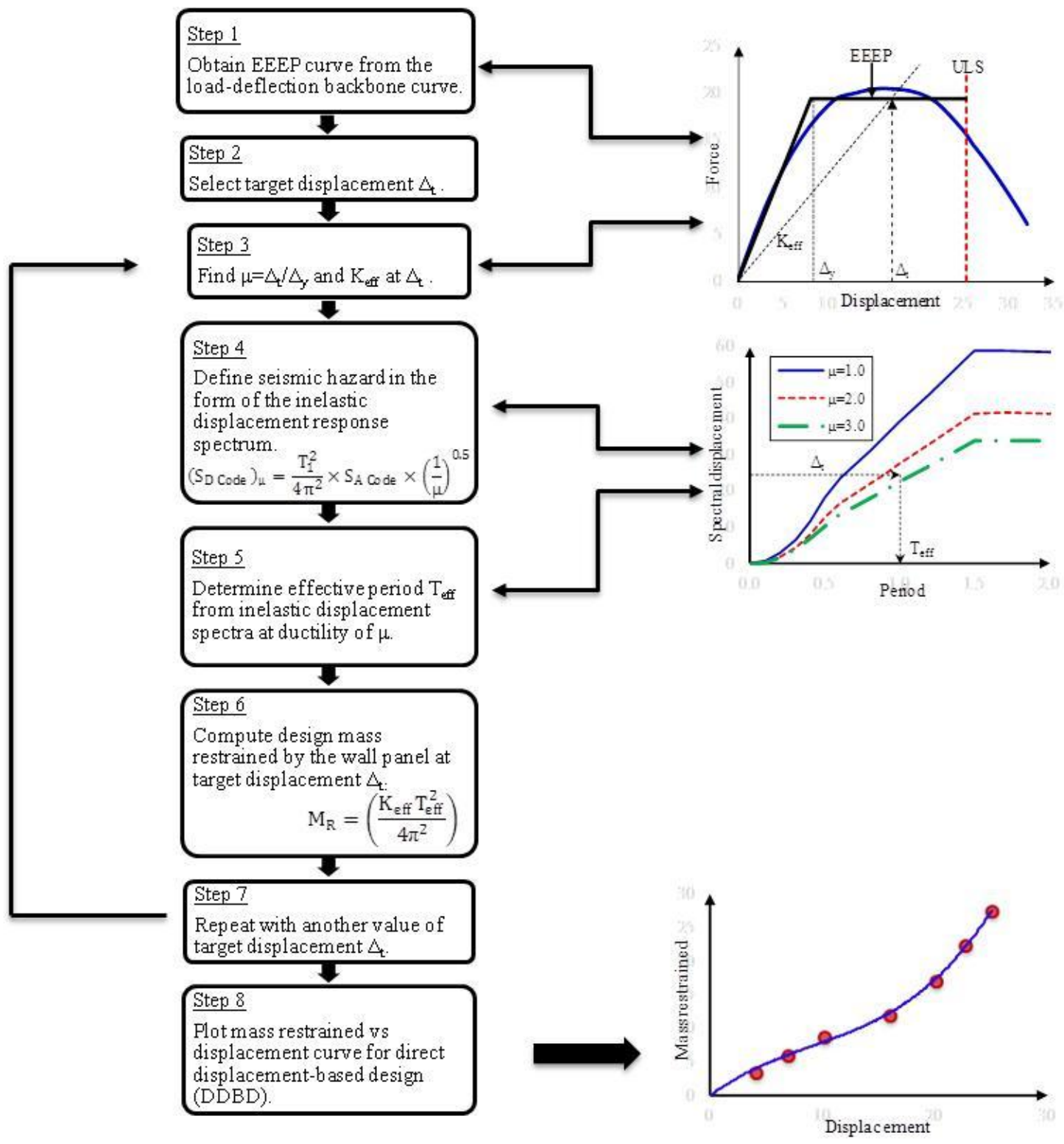

Fig. 2 Generation of DDBD curve based on inelastic displacement response spectrum approach

\section{Numerical example illustrating DDBD curve generation}

\subsection{Structural configuration and wall parameters}

DDBD curves that have been derived using the two modelling approaches to illustrate the method for cold-formed steel stud bracing wall panels as shown in Figure 3. These wall configurations have been investigated experimentally by Shahi et al. (2016). The dimensions of the wall panels were $2.4 \mathrm{mx} 2.4 \mathrm{~m}$ (FCB-A) and $2.4 \mathrm{mx} 0.9 \mathrm{~m}$ (FCB-B). The wall panels were built from CFS framing members and fibre cement sheathing panels. The CFS frame was made of $89 \times 36 \times 0.75 \mathrm{~mm}$ C-shaped lipped studs (with web stiffened) and $91 \times 40 \times 0.75 \mathrm{~mm}$ 
plain channel sections for plates and noggings. Studs were placed at $600 \mathrm{~mm}$ spacings for $2.4 \mathrm{~m}$ long wall and $450 \mathrm{~mm}$ spacings for $0.9 \mathrm{~m}$ long wall. Two identical fibre cement boards of $5 \mathrm{~mm}$ in thickness were used as sheathing boards for wall panel FCB-A whereas one board of $5 \mathrm{~mm}$ in thickness was used for wall panel FCB-B. The sheathing boards were attached vertically on one face of the wall panel. Refer Shahi et al. (2016) for more details of the test setup and loading conditions. Load-deflection curves of the wall panels tested under quasistatic cyclic loading are presented in Figure 4. Equivalent Energy Elastic-Plastic (EEEP) curves, and the recommended viscous damping values, both of which are required for the application of the DDBD approach, are presented in Figures 5 and 6 respectively.

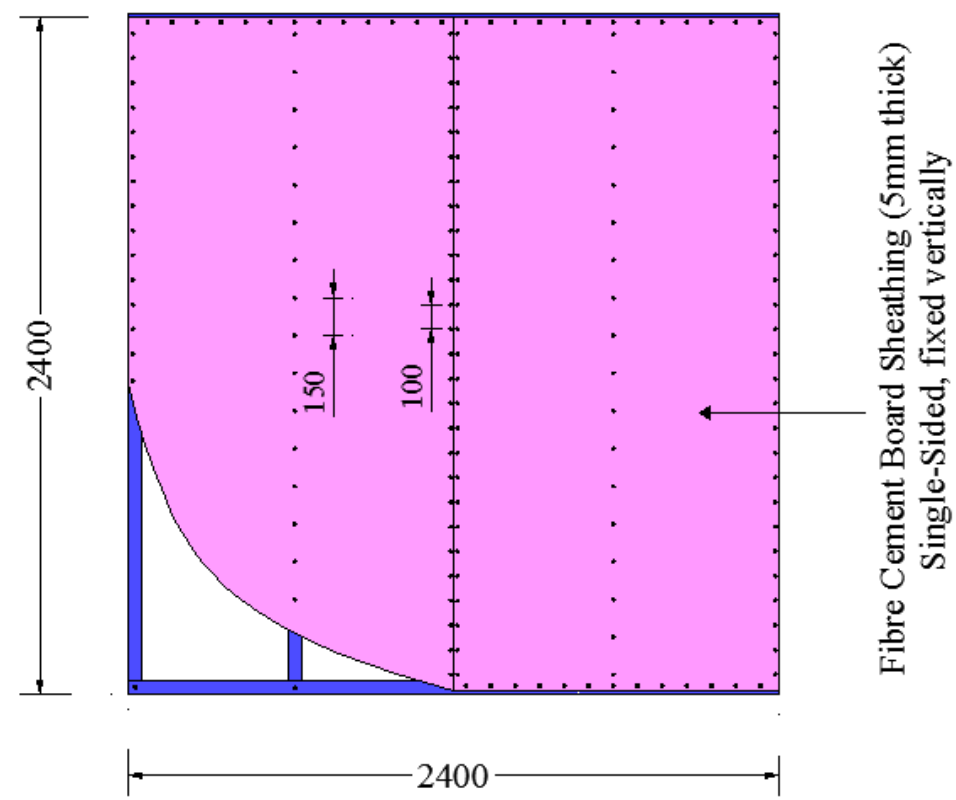

(a)

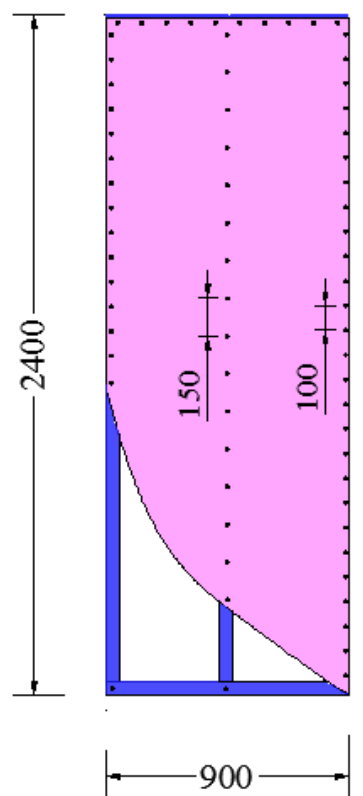

(b)

Fig. 3 Wall panel configurations (Shahi et al. 2016): (a) FCB-A; and (b) FCB-B

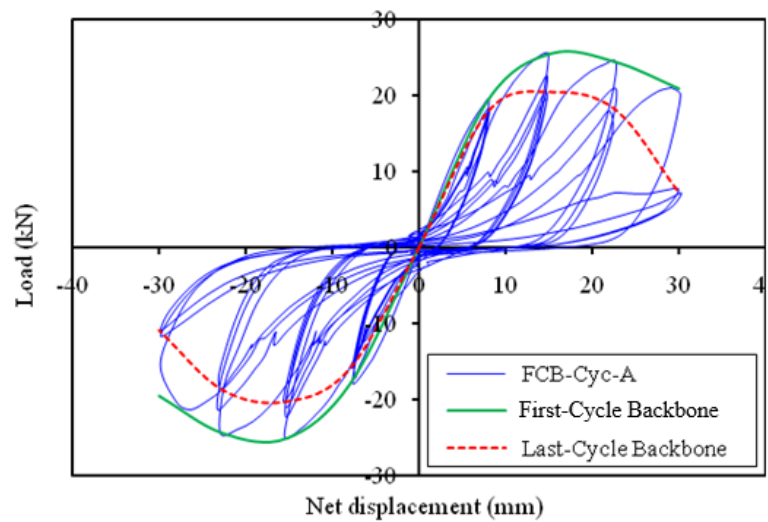

(a)

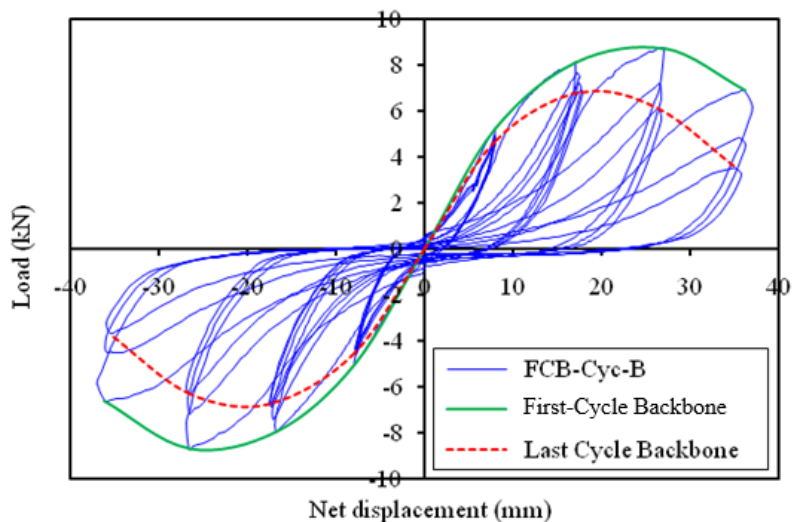

(b)

Fig. 4 Load-deflection curves of tested wall panels from cyclic loading (Shahi et al. 2016): (a) FCB-A; and (b) FCB-B 


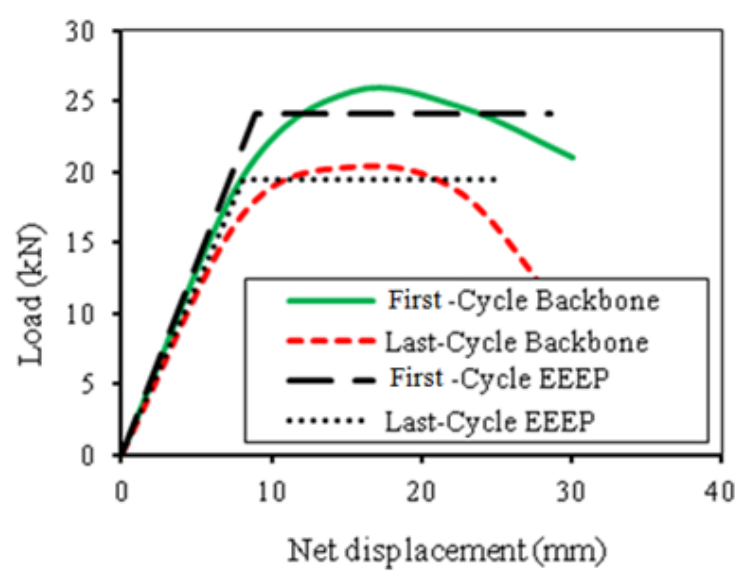

(a)

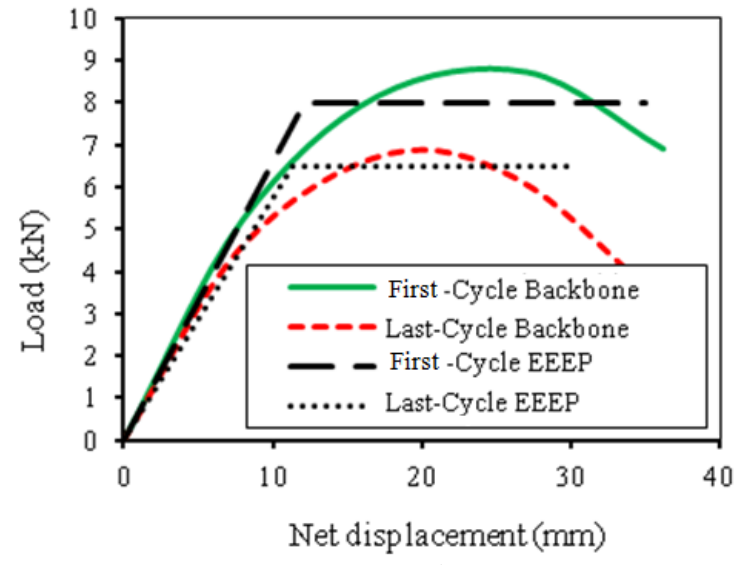

(b)

Fig. 5 EEEP curves of tested wall panels (Shahi et al. 2016): (a) FCB-A; and (b) FCB-B

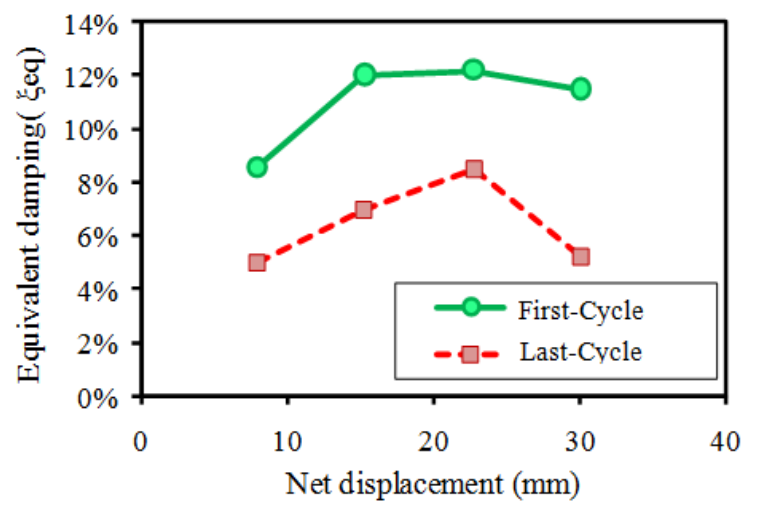

(a)

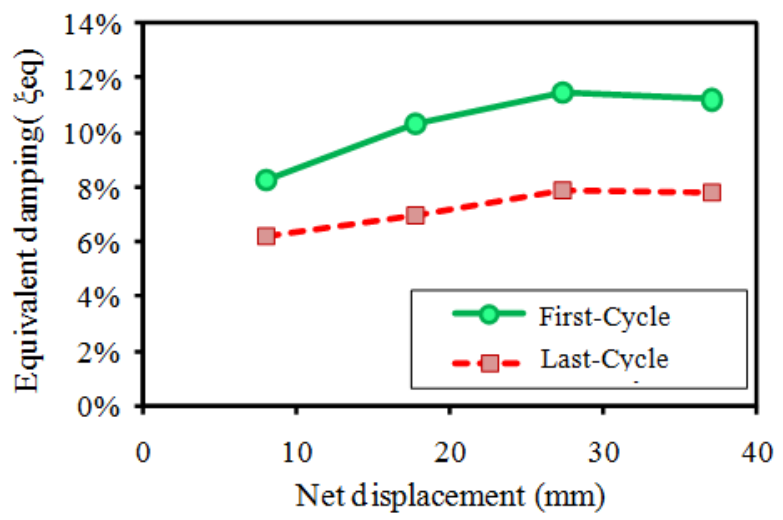

(b)

Fig. 6 Equivalent viscous damping properties of tested wall panels: (a) FCB-A; and (b) FCB-B

\subsection{DDBD curves}

By applying the two modelling procedures introduced in this paper (Refer Figures 1 and 2 respectively) DDBD curves were generated for tested wall specimens FCB-A and FCB-B using first, and last-cycle, EEEP curves as presented in Figure 5. The amount of mass that can be restrained at various levels of target displacement demand for the two wall panels (FCB-A and FCB-B) are shown in Figure 7 (from DDBD based on the equivalent viscous damping approach) and Figure 8 (from DDBD based on the inelastic displacement response spectrum approach). A numerical example illustrating each step of the calculation for generating the DDBD curve based on the last-cycle EEEP curve of the wall panel: FCB-A is presented in Table 1. These results are also presented graphically in Figure 8(a) (shown by legend Last-Cycle $(D D B D))$. It is shown that DDBD curves generated using equivalent damping approach and inelastic displacement response spectrum approach can be very different even for the same wall panel. It was uncertain which approach produced more accurate results. There are also uncertainties as to whether the first-cycle, or the last-cycle, EEEP curve should be used for the generation of the DDBD curves. In order to resolve the uncertainties, validation of the DDBD curve is necessary and was carried out by comparing results generated by the proposed methodology with those from non-linear time history analyses (NLTHA) as presented in Section 3.3. 


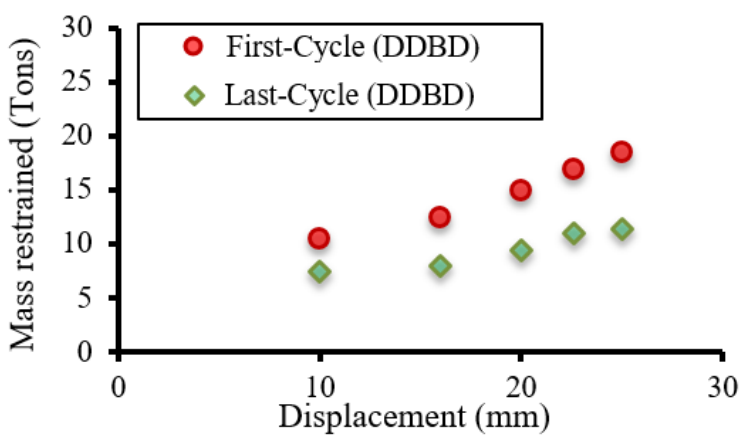

(a)

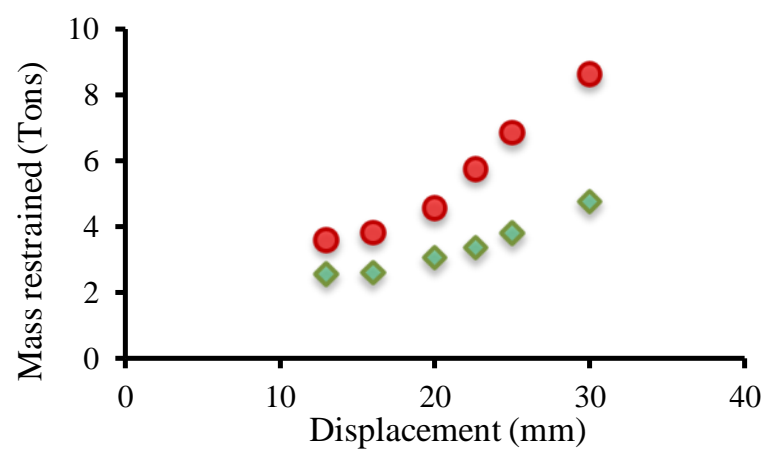

(b)

Fig. 7 DDBD curves using equivalent damping: (a) FCB-A; and (b) FCB-B

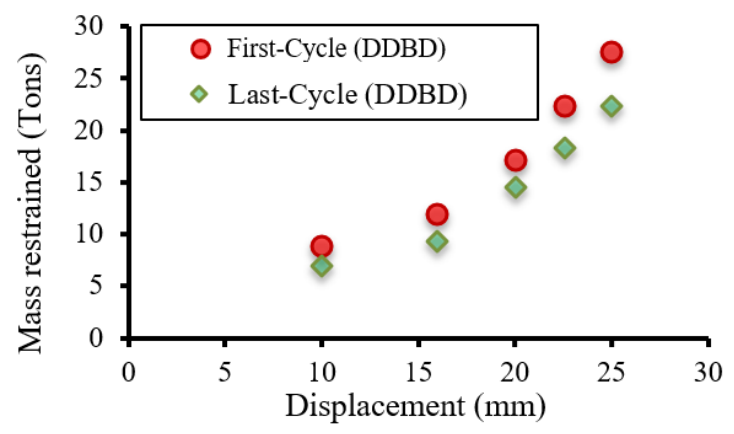

(a)

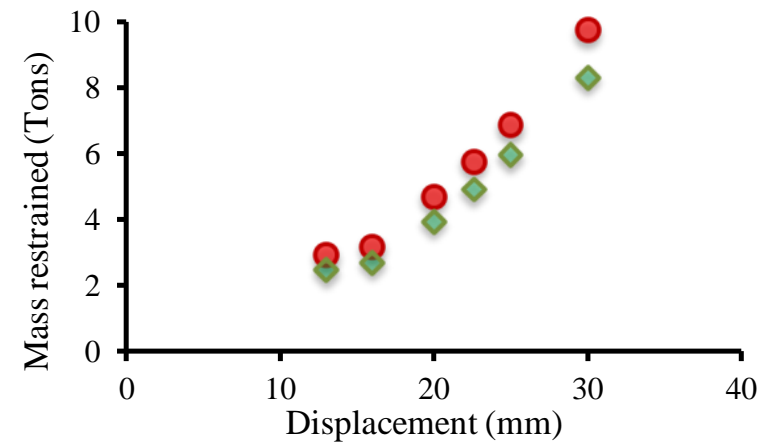

(b)

Fig. 8 DDBD curves using inelastic displacement response spectra: (a) FCB-A; and (b) FCB-B 
Table 1 A numerical example illustrating the step-by-step procedure for generating DDBD curve for wall panel FCB-A using inelastic spectra

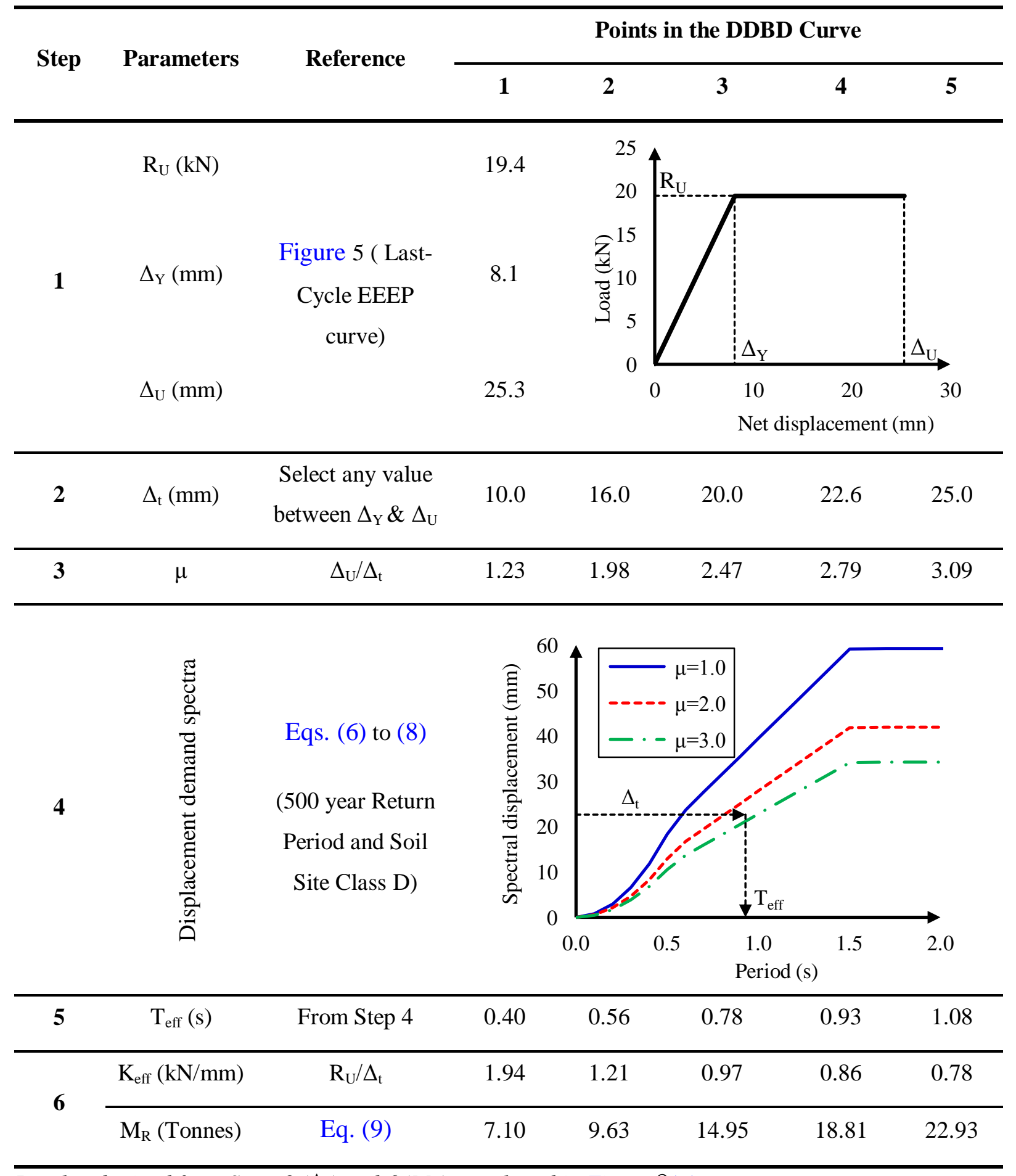

Results obtained from Steps $2\left(\Delta_{\mathrm{t}}\right)$ and $6\left(M_{R}\right)$ are plotted in Figure 8(a) 


\subsection{Comparison with non-linear time history analyses}

In order to conduct non-linear time history analyses (NLTHA), a wall panel was modelled as an equivalent single-degree-of-freedom (SDOF) system based on the use of a non-linear hysteretic spring element SAWS (Folz and Filiatrault 2001). SAWS parameters that closely fit the hysteretic curve of the tested wall panels FCB-A and FCB-B are shown in Figure 9. Recorded earthquakes sourced from the PEER database as listed in Table 2, were used for performing NLTHA. The records have been modified to match with the design target spectrum using SeismoMatch V2.1 (Seismosoft 2013) in order that results from NLTHA should be consistent, and comparable, with those obtained from the DDBD approach (as presented in Section 3). The resulting response spectra of recorded accelerograms that are consistent with pre-defined target spectrum are provided in Figure 10. NLTHA were carried out using program SAPWood (Pei and van de Lindt 2010) on SDOF systems which employed a non-linear SAWS spring that supports a variable tributary mass. Since the hysteretic element has been calibrated to capture the global response behaviour of the wall panel (encapsulating various energy dissipating mechanisms), a nominal viscous damping of $1 \%$ is introduced in the model to ensure convergence of the numerical solution. The peak displacement value obtained from each time history run is plotted against the value of the tributary mass to generate the mass vs displacement demand relationships as shown in Figure 11 for comparison with Figures 7 and 8. It is observed from Figure 13 that the "last-cycle" DDBD curves derived from the inelastic displacement response spectrum approach provide much better correlation with NLTHA results. Hence, the last-cycle DDBD curve as derived from the inelastic displacement response spectrum approach is recommended for use in the seismic assessment of the wall panel (refer Section 4). Table 3 provides a list of the nominal, and design, values of the amount of "mass restrained" by the wall panel at various levels of displacement. Results for wall panels FCB-A and FCB-B as obtained from the inelastic response spectrum approach of the DDBD and from NLTHA are also compared in Table 3.

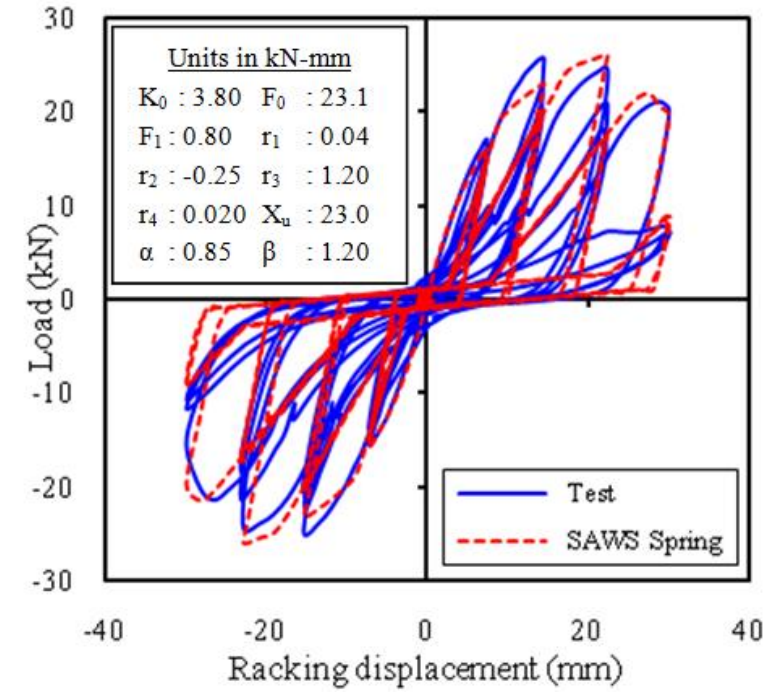

(a)

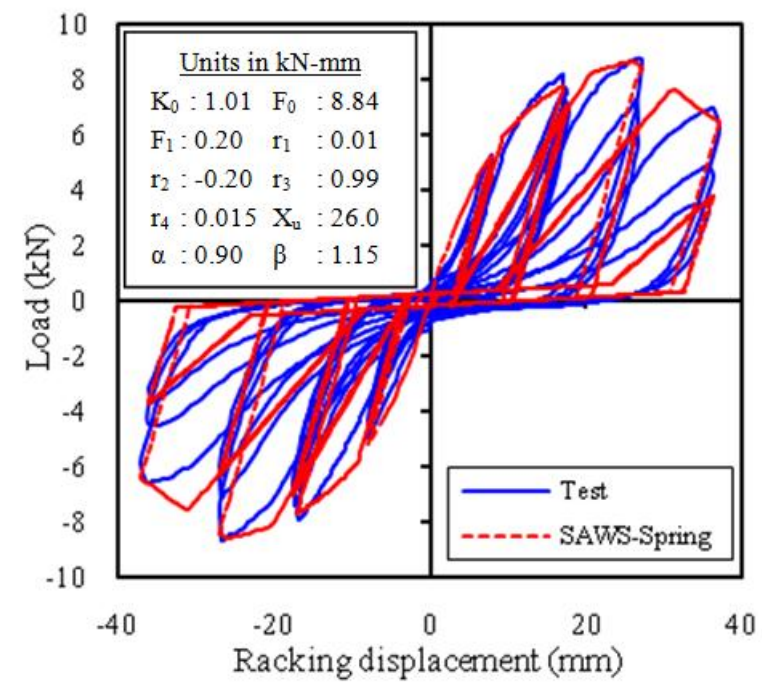

(b)

Fig. 9 SAWS parameters fitting the hysteretic curves of tested wall panels: (a) FCB-A; and (b) FCB-B 
Table 2 List of recorded earthquake accelerograms employed for NLTHA

\begin{tabular}{clcccccccc}
\hline No. & Event & Component & Year & Station & $\mathbf{M}^{\mathbf{1}}$ & $\begin{array}{c}\mathbf{R}^{2} \\
(\mathbf{k m})\end{array}$ & $\begin{array}{c}\text { Vs30 }^{\mathbf{3}} \\
(\mathbf{m} / \mathbf{s})\end{array}$ & $\begin{array}{c}\mathbf{P G A}^{\mathbf{4}} \\
(\mathbf{g})\end{array}$ & $\begin{array}{c}\mathbf{P G V}^{\mathbf{5}} \\
(\mathbf{m m} / \mathbf{s})\end{array}$ \\
\hline 1 & San Fernando & $\mathrm{FN}^{*}$ & 1971 & Pearblossom Pump & 6.61 & 39.0 & 529 & 0.135 & 46.5 \\
2 & San Fernando & $\mathrm{FP}^{+}$ & 1971 & Pearblossom Pump & 6.61 & 39.0 & 529 & 0.130 & 46.1 \\
3 & Northridge-01 & $\mathrm{FN}^{*}$ & 1994 & $\begin{array}{c}\text { Alhambra-Fremont } \\
\text { School }\end{array}$ & 6.69 & 36.8 & 550 & 0.100 & 81.3 \\
4 & Northridge-01 & $\mathrm{FP}^{+}$ & 1994 & Alhambra-Fremont & 6.69 & 36.8 & 550 & 0.080 & 99.0 \\
5 & Northridge-01 & $\mathrm{FN}^{*}$ & 1994 & Leona Valley \#1 & 6.69 & 37.2 & 685 & 0.108 & 78.9 \\
6 & Northridge-01 & $\mathrm{FP}^{+}$ & 1994 & Leona Valley\#1 & 6.69 & 37.2 & 685 & 0.046 & 63.4 \\
7 & Northridge-01 & $\mathrm{FN}^{*}$ & 1994 & Leona Valley \#3 & 6.69 & 37.3 & 685 & 0.099 & 82.6 \\
8 & Northridge-01 & $\mathrm{FP}^{+}$ & 1994 & Leona Valley \#3 & 6.69 & 37.3 & 685 & 0.068 & 93.5 \\
9 & Northridge-01 & $\mathrm{FN}^{*}$ & 1994 & $\begin{array}{c}\text { Palmdale-Hwy } 14 \\
\text { \& Palmdale }\end{array}$ & 6.69 & 41.7 & 552 & 0.074 & 64.3 \\
10 & Northridge-01 & $\mathrm{FP}^{+}$ & 1994 & Palmdale-Hwy 14 & 6.69 & 41.7 & 552 & 0.069 & 107.4 \\
11 & Chi-Chi-Taiwan-06 & $\mathrm{FP}^{+}$ & 1999 & CHY029 & 6.30 & 41.4 & 545 & 0.118 & 108.4 \\
12 & Chi-Chi-Taiwan-06 & $\mathrm{FP}^{+}$ & 1999 & CHY087 & 6.30 & 56.3 & 505 & 0.085 & 91.7 \\
\hline
\end{tabular}

${ }^{1}$ Moment magnitude, ${ }^{2}$ Closest distance to fault rupture, ${ }^{3}$ Average shear wave velocity of top 30 meters of the site, ${ }^{4}$ Peak ground acceleration, ${ }^{5}$ Peak ground velocity, ${ }^{*}$ Fault-normal, ${ }^{+}$Fault-parallel

Source: PEER Strong Motion Database, http://peer.berkeley.edu/peer_ground_motion_database/ 


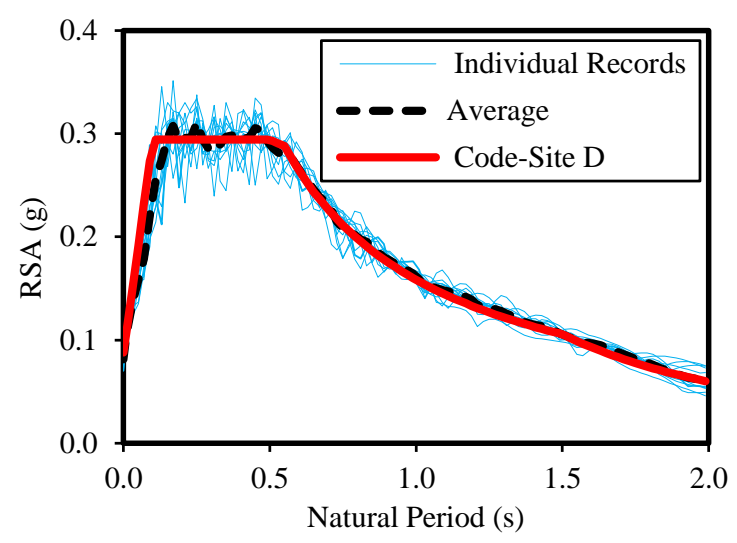

(a)

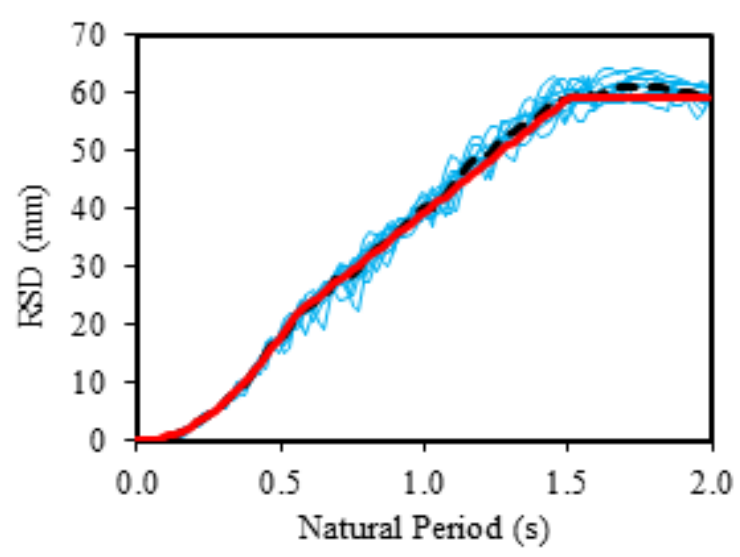

(c)

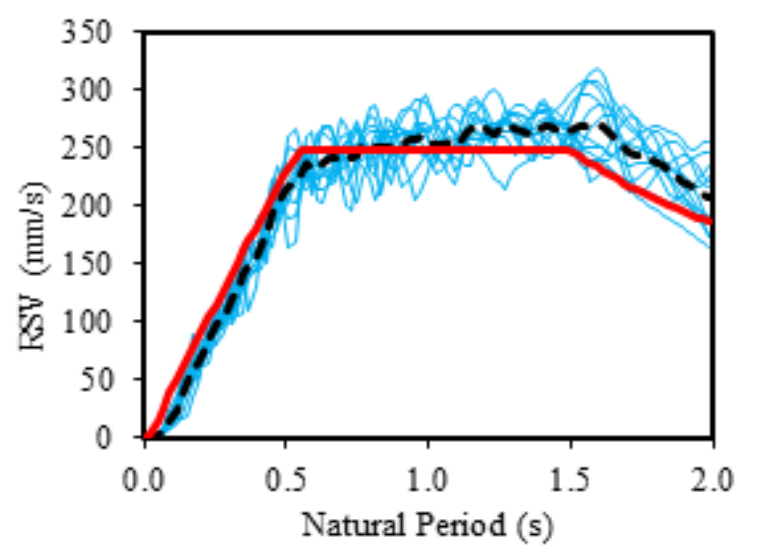

(b)

Fig. 10 Response spectra of considered earthquakes for NLTHA: (a) Response Spectrum Acceleration (RSA); (b) Response Spectrum Velocity (RSV); and (c) Response Spectrum Displacement (RSD)

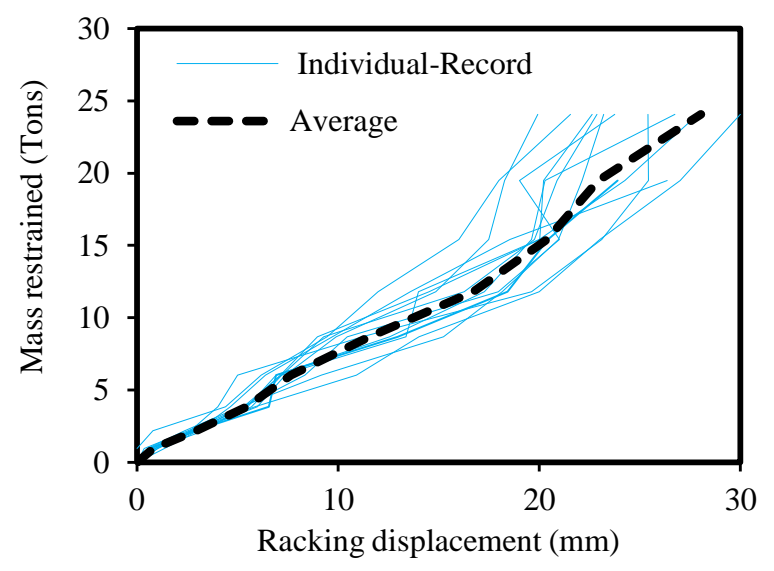

(a)

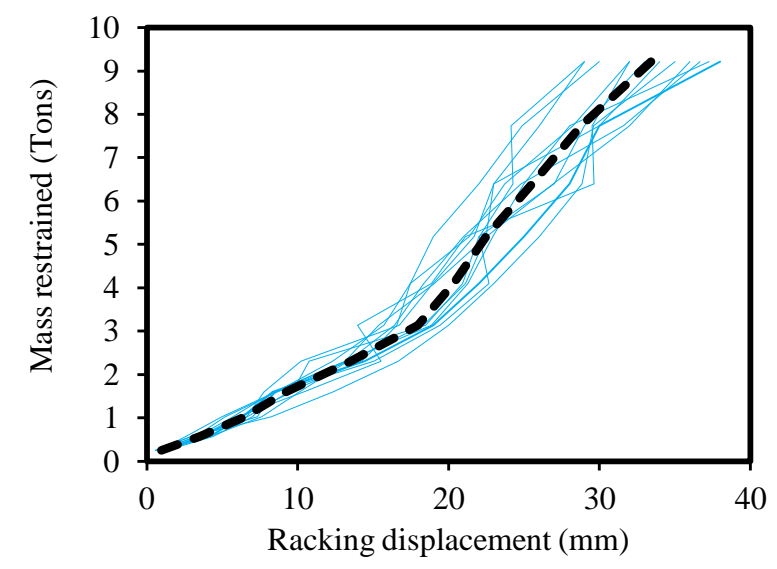

(b)

Fig. 11 Mass restrained at various racking displacements obtained from NLTHA: (a) FCB-A; and (b) FCB-B 


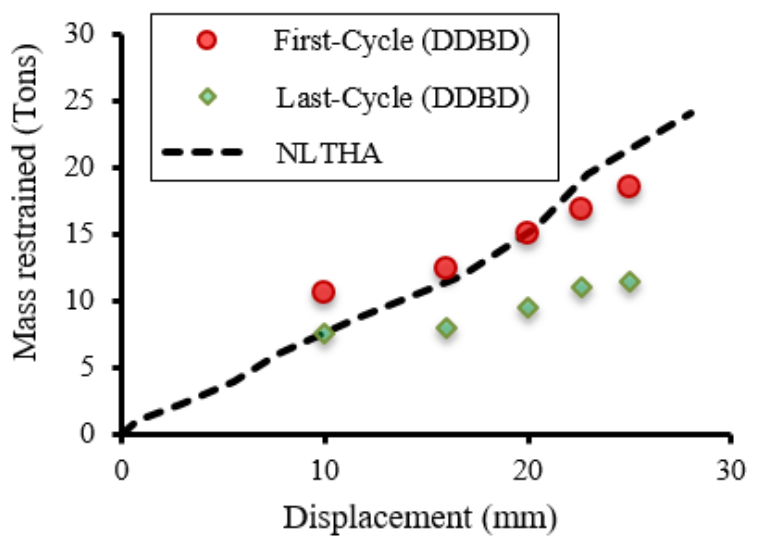

(a)

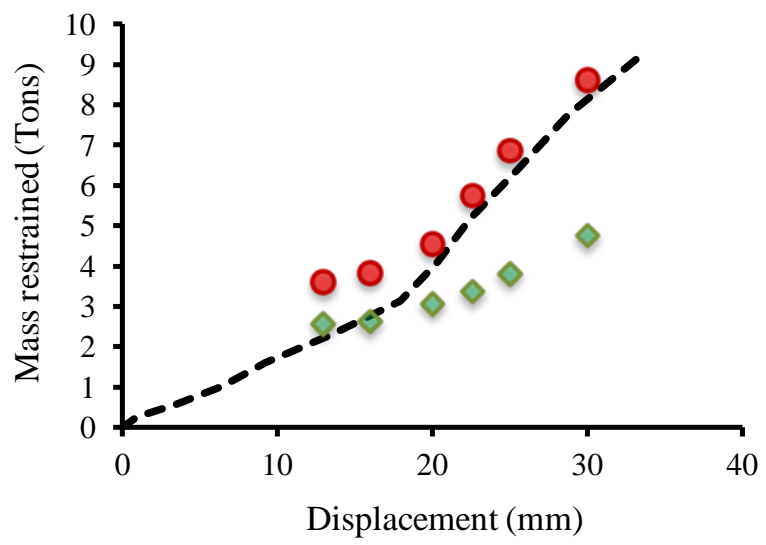

(b)

Fig. 12 Comparison of the DDBD curves using equivalent damping, with NLTHA results: (a) FCB-A; and (b) FCB-B

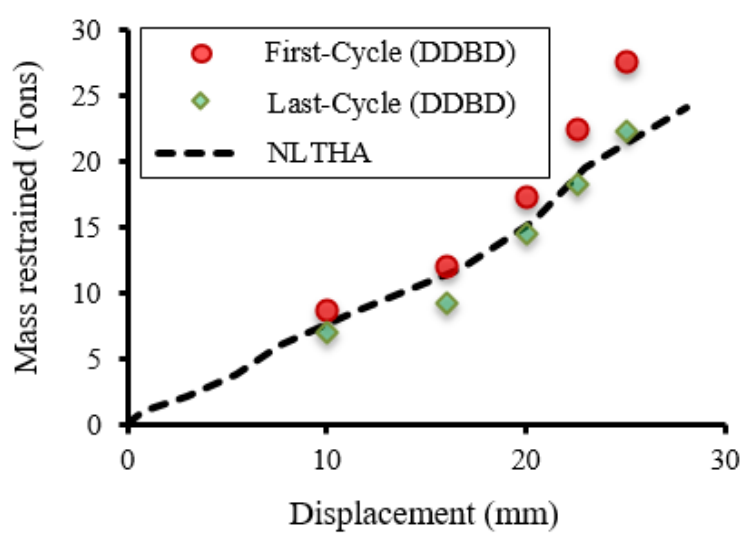

(a)

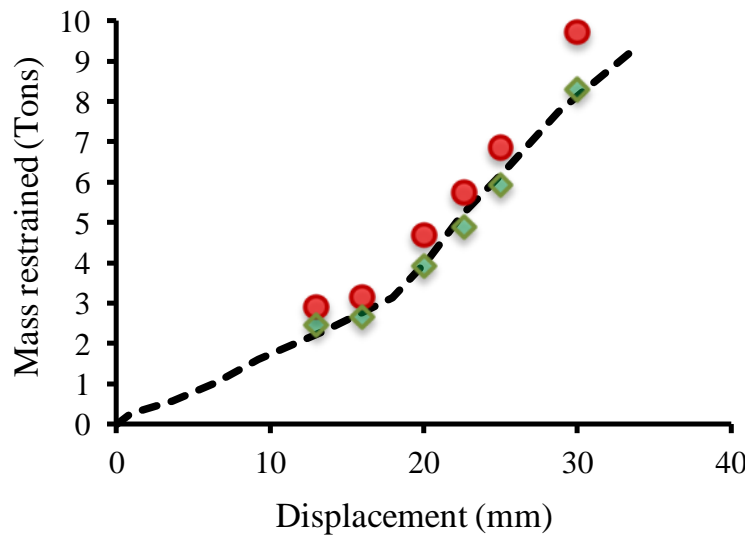

(b)

Fig. 13 Comparison of the DDBD curves using inelastic displacement response spectra, with

NLTHA results: (a) FCB-A; and (b) FCB-B 
Table 3 Comparison of the amount of "mass restrained" by the wall panel obtained from DDBD derived from inelastic displacement spectra approach, with NLTHA results

\begin{tabular}{|c|c|c|c|c|c|c|c|c|c|}
\hline \multirow{2}{*}{$\begin{array}{l}\text { Wall } \\
\text { panel }\end{array}$} & \multirow{2}{*}{$\underset{(\mathbf{m m})}{\Delta}$} & \multicolumn{3}{|c|}{$\begin{array}{c}\text { Nominal mass restrained }^{1} \\
\text { (Tonnes) }\end{array}$} & \multicolumn{3}{|c|}{$\begin{array}{c}\text { Design mass restrained }^{2} \\
\text { (Tonnes) }\end{array}$} & \multicolumn{2}{|c|}{ Ratio } \\
\hline & & $\begin{array}{l}\text { First } \\
\text { Cycle }\end{array}$ & $\begin{array}{l}\text { Last } \\
\text { Cycle }\end{array}$ & NLTHA & $\begin{array}{l}\text { First } \\
\text { Cycle }\end{array}$ & $\begin{array}{l}\text { Last } \\
\text { Cycle }\end{array}$ & NLTHA & $\frac{\text { First - Cycle }}{\text { NLTHA }}$ & $\frac{\text { Last }- \text { Cycle }}{\text { NLTHA }}$ \\
\hline \multirow{5}{*}{$\begin{array}{l}\text { FCB- } \\
\text { A }\end{array}$} & 10 & 8.7 & 6.9 & 7.5 & 3.9 & 3.1 & 3.4 & 1.16 & 0.92 \\
\hline & 16 & 12.0 & 9.3 & 11.2 & 5.4 & 4.2 & 5.1 & 1.07 & 0.83 \\
\hline & 20 & 17.2 & 14.5 & 15.2 & 7.8 & 6.6 & 6.9 & 1.13 & 0.95 \\
\hline & 22.6 & 22.4 & 18.2 & 18.8 & 10.1 & 8.2 & 8.5 & 1.19 & 0.97 \\
\hline & 25 & 27.4 & 22.2 & 22.0 & 12.4 & 10.0 & 10.0 & 1.25 & 1.01 \\
\hline \multirow{6}{*}{$\begin{array}{l}\text { FCB- } \\
\text { B }\end{array}$} & 13 & 2.9 & 2.5 & 2.1 & 1.3 & 1.1 & 1.0 & 1.63 & 1.38 \\
\hline & 16 & 3.2 & 2.7 & 2.7 & 1.4 & 1.2 & 1.2 & 1.16 & 0.98 \\
\hline & 20 & 4.7 & 3.9 & 4.0 & 2.1 & 1.8 & 1.8 & 1.17 & 0.98 \\
\hline & 22.6 & 5.7 & 4.9 & 5.1 & 2.6 & 2.2 & 2.3 & 1.13 & 0.96 \\
\hline & 25 & 6.9 & 5.9 & 6.2 & 3.1 & 2.7 & 2.8 & 1.11 & 0.96 \\
\hline & 30 & 9.7 & 8.3 & 8.2 & 4.4 & 3.8 & 3.7 & 1.18 & 1.01 \\
\hline
\end{tabular}

${ }^{1}$ Nominal mass restrained obtained from DDBD and NLTHA

${ }^{2}$ Design mass restrained $=$ Nominal mass restrained $/ \mathrm{K}_{\mathrm{t}}$ where $\mathrm{K}_{\mathrm{t}}$ is the sampling factor $=2.21$ for 1 sample tested with $20 \%$ coefficient of variation (NASH 2005)

\section{Seismic assessment of wall panel using DDBD curve}

This section demonstrates the use of the DDBD curve for the seismic assessment of a wall panel. A flow chart illustrating various steps involved in the DDBD seismic assessment procedure is presented in Figure 14. The DDBD curve as obtained from the last-cycle EEEP curve using the inelastic displacement response spectrum approach was used for the seismic assessment (as this method demonstrates better estimates of the amount of mass that can be restrained than the other methods introduced in this paper). Wall panel (FCB-A, shown in Figure 3a) supporting a seismic weight of $60 \mathrm{kN}$ is used as an example for illustration. A typical wall panel wastaken fromthe CFS house shown in Figure 15 and a step-by-step procedure for calculating the demand/capacity (D/C) ratio for the example wall panel is presented in Figure 16. 
Step 1

Determine the seismic weight $\left(W_{t}\right)$ supported by the wall panel.

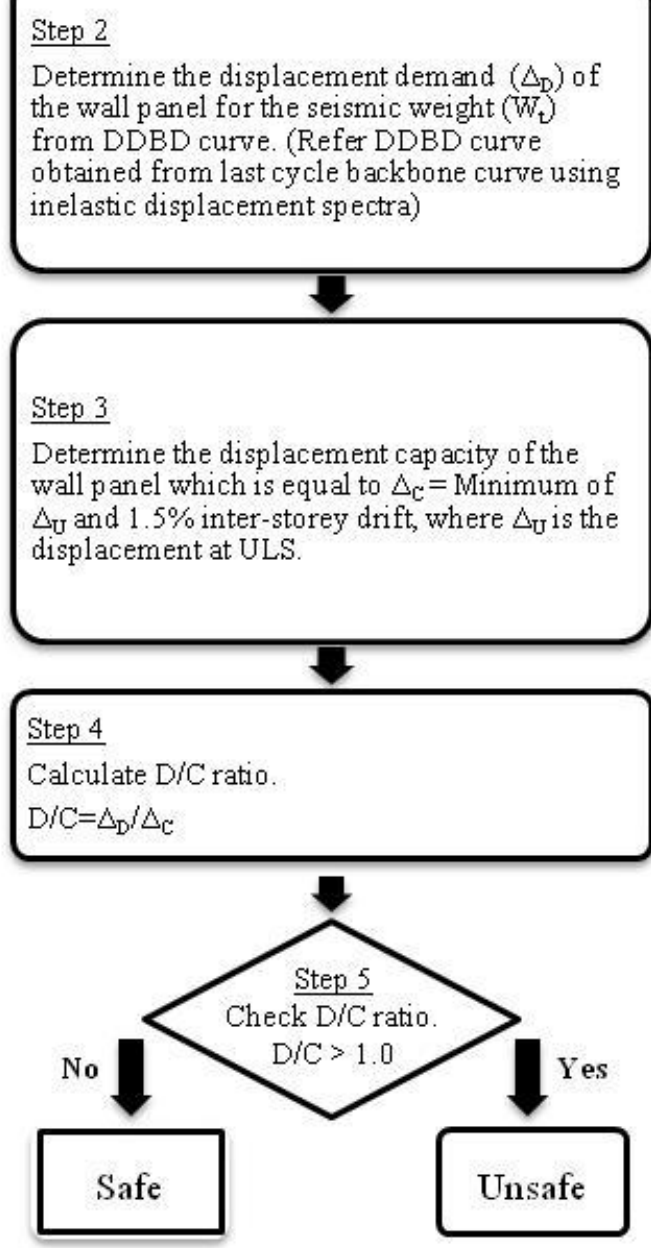

Fig. 14 Seismic assessment of wall panel using DDBD approach 

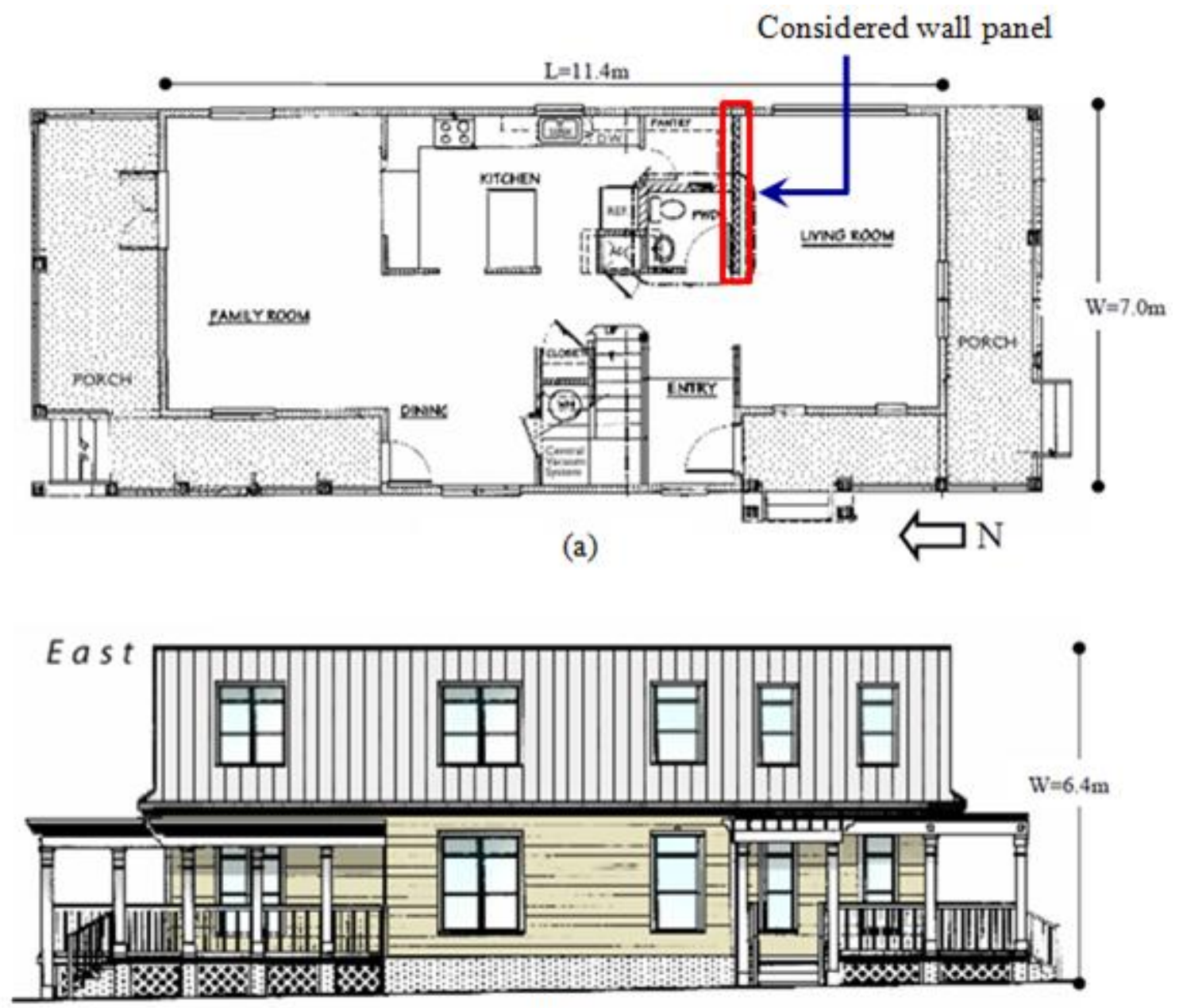

(b)

Fig. 15 Typical cold-formed steel-framed domestic structure (Fiorino 2003): (a) First floor plan; and (b) East elevation

Step 1. Seismic weight, $\mathrm{W}_{\mathrm{t}}=120 \mathrm{kN}$

Step 2. Determine displacement demand $\left(\Delta_{\mathrm{D}}\right)$ for seismic weight of $60 \mathrm{kN}=6.1$ Tons (designed values of "mass restrained"), $\Delta_{\mathrm{D}}=19.2 \mathrm{~mm}$ (Refer Table III, Last-cycle DDBD)

Step 3. Find displacement capacity of the wall panel,

$$
\Delta_{\mathrm{C}}=\text { Lesser of }\left\{\begin{array}{c}
\Delta_{\mathrm{U}}=25.3 \mathrm{~mm}(\text { Refer Table I) } \\
1.5 \% \text { inter storey drift }=36 \mathrm{~mm} \text { for } 2.4 \mathrm{~m} \text { height wall }
\end{array}=25.3 \mathrm{~mm}\right.
$$

Step 4. $\quad \mathrm{D} / \mathrm{C}=\Delta_{\mathrm{D}} / \Delta_{\mathrm{C}}=19.2 / 25.3=\mathbf{0 . 7 6}<1.0 \rightarrow \underline{\text { Safe }}$

Fig. 16 Step-by-step calculations of seismic assessment of wall panel FCB-A using DDBD approach 


\section{Conclusions}

This paper presents a framework for the application of the direct-displacement based design (DDBD) approach for assessing the bracing capacity of cold-formed steel stud bracing wall panels, particularly for earthquake loading. The DDBD method is presented with two different approaches for assessing the bracing capacity of wall panels: (i) equivalent damping; and (ii) inelastic displacement response spectra. Non-linear time history analyses (NLTHA) have been conducted for a suite of artificial, and recorded, accelerograms consistent with the design level earthquake for checking accuracies of the adopted DDBD approach. It is shown that results estimated from the DDBD methodology based on the inelastic displacement response spectrum approach (associated with the last-cycle loaddeflection backbone curve) correlated better with results from NLTHA (than those derived from the equivalent viscous damping approach). Designers including engineers and system developers are offered the option of adopting DDBD curves for the seismic resistant design, or performance assessment, of wall panels built of cold formed steel.A sample demonstration for the seismic assessment of the wall panel from a typical CFS house is also presented in the paper. Designer/manufacturer can make use of the DDBD curves for estimating the bracing capacity of the wall panel and for developing seismic wall rating table, or charts. A procedure for developing seismic rating of the bracing wall panel is currently under study. It should be noted that this study has not considered influences from interactions between the wall panels.

Acknowledgements This research is funded by the ARC Linkage Project LP110100430. The authors gratefully acknowledge the financial and technical support provided by the collaborating organization, the National Association of Steel-framed Housing (NASH).

\section{References}

Eurocode 8 (EN 1998-1) (2004) Design of structures for earthquake resistance-Part 1: General rule, seismic actions and rule for buildings. European Committee for Standardisation, Brussels.

Fiorino L (2003) Seismic behaviour of sheathed cold-formed steel stud shear walls: An experimental investigation. $\mathrm{PhD}$ thesis, Università degli Studi di Napoli Federico II, Napoli, Italy.

Folz B, Filiatrault A (2001) Cyclic analysis of wood shear walls. Journal of Structural Engineering 127(4):433-441.

Lam NTK, Wilson JL, Chandler AM (2001) Seismic displacement response spectrum estimated from the frame analogy soil amplification model. Engineering Structures 23(11):1437-1452.

Landolfo R, Fiorino L, Della CG (2006) Seismic behaviour of sheathed cold-formed structures: Numerical study. Journal of Structural Engineering 132(4):558-569.

NASH Standard (2005) Residential and low-rise steel framing-Part 1: Design Criteria. National Association of Steel-framed Housing Inc., VIC, Australia.

Nithyadharan M, Kalyanaraman V (2012) Behaviour of cold-formed steel shear wall panels under monotonic and reversed cyclic loading. Thin-Walled Structures 60:12-23.

PEER ground motion database, http://peer.berkeley.edu/peer_ground_motion_database/, viewed on $25^{\text {th }}$ March 2013.

Pei S, van de Lindt JW (2010) User's manual for SAPWood for Windows, Version 2.0. 
Priestley MJN (1993) Myths and fallacies in earthquake engineering-conflicts between design and reality. Bulletin of the New Zealand National Society for Earthquake Engineering, 26(3):329-341.

Priestley MJN (1998) Displacement-based approaches to rational limit states design of new structures, Keynote Address. Proceedings in the $11^{\text {th }}$ European Conference on Earthquake Engineering.

Priestley MJN (2000) Performance based seismic design. Proceedings in the $12^{\text {th }}$ World Conference on Earthquake Engineering. Auckland, New Zealand.

Priestley MJN, Calvi GM, Kowalsky MJ (2007) Displacement based seismic design of structures. Pavia, Italy.

Seismosoft (2013) SeismoMatch V2.1 - A computer program for spectrum matching of earthquake records.

Shahi R, Lam N, Gad E, Wilson J, Watson K (2016) Seismic performance behavior of coldformed steel wall panels by quasi-static tests and incremental dynamic analyses. Journal of Earthquake Engineering, DOI: 10.1080/13632469.2016.1160007.

Standard Australia (AS1170.4) (2007) Structural design actions-Part 4 Earthquake actions in Australia. 


\section{University Library}

\section{- M M N E R VA A gateway to Melbourne's research publications}

Minerva Access is the Institutional Repository of The University of Melbourne

Author/s:

Shahi, R;Lam, N;Gad, E;Wilson, J;Watson, K

Title:

Seismic assessment of cold-formed steel stud bracing wall panels using direct displacement based design approach

Date:

2017-03-01

Citation:

Shahi, R., Lam, N., Gad, E., Wilson, J. \& Watson, K. (2017). Seismic assessment of coldformed steel stud bracing wall panels using direct displacement based design approach. BULLETIN OF EARTHQUAKE ENGINEERING, 15 (3), pp.1261-1277. https://doi.org/10.1007/ s10518-016-9980-X.

Persistent Link:

http://hdl.handle.net/11343/282727 